\title{
Penilaian iklim keselamatan persekitaran kerja terhadap komuniti kakitangan kerajaan di Putrajaya
}

\author{
Kadir Arifin ${ }^{1}$, Roziah Abudin ${ }^{1}$, Muhammad Rizal Razman ${ }^{2}$ \\ ${ }^{1}$ Program Sains Pembangunan, Pusat Pembangunan, Sosial dan Persekitaran, \\ Fakulti Sains Sosial dan Kemanusiaan, Universiti Kebangsaan Malaysia. \\ ${ }^{2}$ Institut Alam Sekitar dan Pembangunan (LESTARI), Universiti Kebangsaan Malaysia. \\ Correspondence: Kadir Arifin (email: kadir@ukm.edu.my)
}

Received: 15 November 2019; Accepted: 22 November 2019; Published: 25 November 2019

\begin{abstract}
Abstrak
Iklim keselamatan merujuk kepada persepsi yang dikongsi pekerja berkaitan keselamatan persekitaran kerja yang mempengaruhi prestasi keselamatan organisasi. Kajian dijalankan untuk menilai iklim keselamatan di Kementerian Pertanian dan Industri Asas Tani (MOA) Putrajaya melalui persepsi pengendalian aspek keselamatan oleh pihak pengurusan dan pekerja berdasarkan kepada 7 dimensi iklim keselamatan. Dimensi iklim keselamatan ialah (i) keutamaan, komitmen dan kecekapan keselamatan pihak pengurusan, (ii) pemerkasaan aspek keselamatan pihak pengurusan, (iii) keadilan keselamatan pihak pengurusan, (iv) komitmen keselamatan pekerja, (v) keutamaan keselamatan dan risiko tidak diterima pekerja, (vi) komunikasi, pembelajaran dan kepercayaan kompetensi rakan sekerja (vii) kepercayaan pekerja terhadap keberkesanan sistem keselamatan. Pendekatan kuantitatif digunakan dengan mengedarkan soal-selidik sebanyak 205 responden di MOA. Soal selidik kajian menggunakan Nordic Occupational Safety Climate Questionnaire (NOSACQ-50) iaitu satu alat diagnostik menilai status iklim keselamatan organisasi. Data dianalasis secara deskriftif melalui min dan peratusan. Hasil kajian menunjukkan secara keseluruhan iklim keselamatan di MOA adalah pada tahap yang agak rendah. Penilaian ke atas tiga dimensi pengendalian aspek keselamatan oleh pihak pengurusan mendapati iklim keselamatan yang agak tinggi bagi dimensi keadilan keselamatan, agak rendah bagi dimensi keutamaan, komitmen dan kecekapan keselamatan serta rendah bagi dimensi pemerkasaan keselamatan. Selanjutnya, penilaian terhadap empat dimensi pengendalian aspek keselamatan oleh pekerja mendapati iklim keselamatan adalah tinggi bagi dimensi kepercayaan terhadap sistem pengurusan keselamatan, agak tinggi bagi dimensi komitmen keselamatan serta dimensi komunikasi, pembelajaran dan kepercayaan terhadap kompetensi rakan sekerja serta agak rendah bagi dimensi keutamaan keselamatan dan risiko tidak diterima. Kajian ini mencadangkan agar pihak pengurusan atasan mampu memperbaiki iklim keselamatan di MOA.
\end{abstract}

Kata kunci: dimensi, iklim keselamatan, kakitangan awam, keberkesanan, persepsi, persekitaran kerja. 


\title{
Work environment safety climate evaluation of government staff community at Putrajaya
}

\begin{abstract}
Safety climate is a term which refers to perceptions that workers share about safety of their work environment, in which it may affect the safety performance of any organization. This study was conducted to analyze the safety climate at the Ministry of Agriculture and Agro-Based Industry (MOA) in Putrajaya through perceptions on the handling of safety aspects by management and employees based on the seven dimensions of the safety climate. The safety climate dimensions are (i) management's priorities, commitments and management safety efficiency, (ii) enhancement of safety aspects of management, (iii) management safety justice, (iv) employee safety commitment, (v) safety precautions and risks are not accepted by employees, (vi) communication, learning and trust in colleague's competencies and (vii) employee beliefs on the effectiveness of the safety system. The method used was using a quantitative approach with the distribution of questionnaires of 205 respondents at the MOA. This survey was conducted using the Nordic Occupational Safety Climate Questionnaire (NOSACQ-50) which is a diagnostic tool to evaluate the status of an organization's safety climate. Data is finally analyzed descriptively through mean and percentage. The result showed that overall the level of safety climate at MOA was fairly low. Evaluation on three dimensions of safety handling by the management was fairly high for safety justice dimension, fairly low for safety priority, commitment and competence dimension and low for safety empowerment dimension. Further evaluation on four dimensions of safety handling by the workers showed a high level of safety climate for trust in the efficacy of safety systems dimension, fairly high for safety commitment dimension and safety communication, learning and trust in co-worker's safety competence dimension and fairly low for safety priority and risk non-acceptance dimension. The analysis of this study also revealed that there were significant differences in safety climate by age group and educational level of the respondents. Therefore, this study proposed safety policy formulation, hazard identification, risk assessment and determining control, establishment of Occupational Safety and Health Committee, safety communication, safety training and change in safety behaviour norms in order to improve safety climate at MOA.
\end{abstract}

Key words: dimension, safety climate, government staff, effectiveness, perception, works environment.

\section{Pengenalan}

Iklim keselamatan merupakan persepsi yang dikongsi oleh pekerja berkaitan keselamatan persekitaran kerja mereka (Zohar, 1980) dan boleh mempengaruhi prestasi keselamatan dan kesihatan sesebuah organisasi (Cooper, 2000; Wu et al., 2007). Skop keselamatan dan kesihatan berkaitan pekerjaan ini amat meluas dan sentiasa dikemas kini supaya seiring dengan perubahan sosial, politik, ekonomi dan teknologi (Alli, 2008; Bryce \& Manga, 1985).

Faktor utama yang membentuk budaya keselamatan organisasi adalah iklim keselamatan (safety climate), tingkah laku dan sistem pengurusan keselamatan (Cooper, 2000). Organisasi 
perlu menilai iklim keselamatan bagi mengetahui persepsi pekerja kerana pekerja yang mempunyai persepsi baik terhadap aspek keselamatan dan kesihatan pekerjaan kurang terlibat dengan insiden kemalangan (Barling et al., 2002). Maklumat berkaitan iklim keselamatan juga penting dalam membantu usaha merancang, melaksana, menilai dan menambah baik strategi berkaitan keselamatan dan kesihatan pekerjaan (Parimalam et al., 2007; Ward et al., 2008; Ima Ilyani et al., 2012). Walaupun persekitaran kerja dalam pejabat yang terdiri daripada kombinasi faktor fizikal (contoh pencahayaan, suhu dan kualiti udara), faktor biologi (contoh kulat, bakteria dan virus), faktor kimia (contoh asap rokok dan bahan pencuci) dan faktor ergonomik (contoh peralatan dan perabot) merupakan potensi hazard yang mendatangkan risiko kemalangan dan penyakit namun ia menjadi fenomena yang diambil mudah (Pidgeon, 1998; Kadir et al., 2012).

Oleh itu kajian ini bertujuan untuk menilai iklim keselamatan di Kementerian Pertanian dan Industri Asas Tani (MOA) berdasarkan persepsi terhadap pengendalian aspek keselamatan oleh pihak pengurusan dan pekerja berasakan kepada skop yang menjurus kepada kakitangan yang bertugas di 11 bahagian di MOA, Wilayah Persekutuan Putrajaya sahaja iaitu kumpulan Pengurusan dan Profesional (gred 41 ke atas) dan kumpulan sokongan (gred 36 ke bawah) sama ada berjawatan tetap, sementara atau kontrak.

\section{Kajian literatur}

\section{Iklim keselamatan}

Zohar (1980) mentakrifkan iklim keselamatan sebagai persepsi yang dikongsi oleh pekerja berkaitan keselamatan persekitaran kerjanya. Beberapa definisi lain turut diketengahkan antaranya Coyle et al. (1995) menyatakan iklim keselamatan adalah pengukuran persepsi dan sikap secara objektif terhadap isu keselamatan dan kesihatan serta Flin et al. (2000) mentakrifkan iklim keselamatan sebagai manifestasi budaya terhasil daripada persepsi dan sikap pekerja. Seterusnya Wu et al. (2007) mendefinisikan iklim keselamatan sebagai persepsi pekerja terhadap keselamatan organisasi di mana persepsi tersebut dipengaruhi oleh faktor organisasi dan faktor individu yang memberi impak kepada tingkahlaku keselamatan. Manakala Cooper (2000) merujuk kepada subset budaya keselamatan dan saling berkaitan dengan faktor tingkahlaku dan sistem pengurusan keselamatan.

Definisi operasional kajian ini ialah mengggunakan takrifan Zohar (1980). Kajian yang memfokuskan kepada pengukuran/penilaian iklim keselamatan ini membantu mengenal pasti masalah asas yang berlaku dalam organisasi dan seterusnya membantu memperbaiki budaya keselamatan kerana budaya keselamatan yang positif dan stabil merupakan fenomena yang berterusan, tidak boleh wujud serta merta dan mengambil masa untuk dibangunkan (Siti Fatimah, 2011; Hale, 2000).

\section{Dimensi iklim keselamatan pekerjaan}

Pemilihan dimensi untuk dinilai dalam kajian iklim persekitaran biasanya bergantung kepada matlamat penyelidikan pengkaji (Huang et al., 2006). Misalnya, kajian 3 dimensi komitmen melibatkan keutamaan pengurusan; keselamatan; dan tekanan pengeluaran oleh Bosak et al. (2013), Cooper dan Phillip (2004) serta Yeung dan Chan (2006) melihat 6 dimensi iaitu sikap dan tindakan pengurusan; risiko; latihan; tekanan kerja; promosi; dan pegawai keselamatan 
pekerjaan. Lu \& Shang (2005) melihat pula kepada 7 dimensi iaitu penyeliaan; keselamatan kerja; rakan sekerja; pengurusan; latihan; peraturan dan latihan khas; dan tekanan kerja. Manakala Huang et al. (2006) dan $\mathrm{Wu}$ et al. (2007) pula masing-masing mengkaji 4 dan 5 dimensi yang berbeza-beza.

Dimensi komitmen, sikap dan tindakan pihak pengurusan terhadap keselamatan telah dikaji sebelum istilah iklim keselamatan diperkenalkan. Kajian oleh Smith et al. (1978) mendapati terdapat perkaitan di antara persepsi tenaga kerja terhadap komitmen keselamatan yang tinggi oleh pihak pengurusan dengan kadar kemalangan yang rendah di 42 buah kilang di Amerika Syarikat.

Dimensi kedua yang digunakan dalam kajian penilaian iklim keselamatan adalah sistem pengurusan keselamatan seperti pegawai keselamatan, jawatankuasa keselamatan, permit bekerja, dasar dan peraturan keselamatan serta peralatan keselamatan (Carder \& Ragan, 2003). Petersen (2005) dan Hale (2000) berpandangan bahawa kajian persepsi dapat memberikan gambaran tepat mengenai kecekapan sistem keselamatan berbanding pengukuran kadar kemalangan kerana ianya tidak dapat menunjukkan sama ada sistem berada dalam keadaan baik atau sebaliknya.

Dimensi risiko yang biasa diliputi dalam kajian iklim keselamatan berkait dengan pengambilan risiko serta kewujudan risiko dan hazard di tempat kerja. Kajian Mearns et al. (1998) dan Rundmo (1995) menunjukkan skor persepsi dan sikap terhadap risiko yang rendah menghasilkan skor iklim keselamatan yang tinggi.

Latihan keselamatan telah lama digunakan sebagai usaha untuk mengubah sikap dan tingkah laku pekerja (Cooper \& Phillips, 2004). Situasi begini biasanya berlaku kerana pekerja beranggapan latihan keselamatan yang diikuti tidak berguna atau tidak efektif (Ima Ilyani et al., 2012; Huang et al., 2006).

Kajian oleh Mearns et al. (2010) menunjukkan komunikasi dapat mengurangkan risiko keselamatan dan memperbaiki keselamatan di persekitaran tempat kerja. Ini disokong oleh kajian Hashish dan El-Bialy (2013) di hospital yang mendapati jururawat tidak melaporkan kesilapan kepada doktor dan pengurus bagi mengelakkan dipersalahkan dan dikenakan tindakan.

\section{Kaedah dan kawasan kajian}

Organisasi kajian adalah Kementerian Pertanian dan Industri Asas Tani (MOA) bertempat di Pusat Pentadbiran Kerajaan Persekutuan, Presint 4, Putrajaya. Kementerian ini telah memulakan operasinya di Putrajaya pada tahun 2004. Pemilihan MOA sebagai organisasi kajian dibuat kerana MOA sedang memulakan usaha untuk menambah baik dan mengukuhkan budaya keselamatan di organisasi tersebut kerana pejabat kerajaan merupakan aset negara dan perlu dipelihara. Oleh kerana penilaian budaya keselamatan mengambil masa yang lama, kebiasaannya penilaian iklim keselamatan dibuat untuk memberikan gambaran budaya keselamatan sedia ada sebagai titik permulaan kepada usaha penambahbaikan dan pengukuhan keselamatan di tempat kerja (Zitty et al., 2017).

Kajian ini merupakan kajian deskriptif yang menggunakan pendekatan kuantitatif. Unit analisis kajian adalah individu yang bertugas di MOA Putrajaya. Kajian melibatkan instrumen pengumpulan data melalui soal selidik yang hanya diedarkan sekali kepada responden. Responden daripada 11 bahagian di MOA terdiri daripada Kumpulan Pengurusan dan 
Profesional (P\&P) gred 41 ke atas dan Kumpulan Sokongan gred 36 ke bawah yang dipilih secara rawak mudah mengikut perincian seperti Jadual 1.

Jadual 1. Jumlah responden

\begin{tabular}{|c|c|c|}
\hline Bahagian & Bilangan & Sampel $(30 \%)$ \\
\hline \multirow[t]{3}{*}{ PSA } & 71 & 21 \\
\hline & $(\mathrm{P} \& \mathrm{P}=24$ & $(\mathrm{P} \& \mathrm{P}=7$ \\
\hline & Sokongan $=47$ ) & Sokongan=14) \\
\hline \multirow[t]{3}{*}{ ITTP } & 44 & 14 \\
\hline & $(\mathrm{P} \& \mathrm{P}=22$ & $(\mathrm{P} \& \mathrm{P}=7$ \\
\hline & Sokongan=22) & Sokongan=7) \\
\hline \multirow[t]{3}{*}{ IPB } & 53 & 16 \\
\hline & Sokongan=32) & $(\mathrm{P} \& \mathrm{P}=6$ \\
\hline & $(\mathrm{P} \& \mathrm{P}=21$ & Sokongan=10) \\
\hline \multirow[t]{3}{*}{ KP } & 287 & 86 \\
\hline & $(\mathrm{P} \& \mathrm{P}=89$ & $(\mathrm{P} \& \mathrm{P}=27$ \\
\hline & Sokongan=198) & Sokongan $=59$ ) \\
\hline \multirow[t]{3}{*}{ BP } & 30 & 9 \\
\hline & $(\mathrm{P} \& \mathrm{P}=13$ & $(\mathrm{P} \& \mathrm{P}=4$ \\
\hline & Sokongan=17) & Sokongan=5) \\
\hline \multirow[t]{3}{*}{ BPSP } & 75 & 22 \\
\hline & $(\mathrm{P} \& \mathrm{P}=42$ & $(\mathrm{P} \& \mathrm{P}=12$ \\
\hline & Sokongan=33) & Sokongan $=10$ ) \\
\hline \multirow{3}{*}{ KSI } & 20 & 6 \\
\hline & $(\mathrm{P} \& \mathrm{P}=10$ & $(\mathrm{P} \& \mathrm{P}=3$ \\
\hline & Sokongan=10) & Sokongan=3) \\
\hline \multirow[t]{3}{*}{ IAT } & 23 & 7 \\
\hline & $(\mathrm{P} \& \mathrm{P}=16$ & $(\mathrm{P} \& \mathrm{P}=5$ \\
\hline & Sokongan=7) & Sokongan=2) \\
\hline \multirow{3}{*}{ PPP } & 17 & 5 \\
\hline & $(\mathrm{P} \& \mathrm{P}=8$ & $(\mathrm{P} \& \mathrm{P}=2$ \\
\hline & Sokongan $=9$ ) & Sokongan=3) \\
\hline \multirow[t]{3}{*}{ BTM } & 27 & 8 \\
\hline & $(\mathrm{P} \& \mathrm{P}=11$ & $(\mathrm{P} \& \mathrm{P}=3$ \\
\hline & Sokongan=16) & Sokongan=5) \\
\hline \multirow[t]{3}{*}{ NATC } & 35 & 11 \\
\hline & $(\mathrm{P} \& \mathrm{P}=13$ & $(\mathrm{P} \& \mathrm{P}=4$ \\
\hline & Sokongan=22) & Sokongan=7) \\
\hline \multirow{3}{*}{ Jumlah } & 682 & 205 \\
\hline & $(\mathrm{P} \& \mathrm{P}=269$ & $(P \& P=80$ \\
\hline & Sokongan=413) & Sokongan $=125$ \\
\hline
\end{tabular}

Sebanyak 205 borang soal selidik telah diedarkan kepada responden yang terdiri daripada Kumpulan P\&P dan Kumpulan Sokongan. Soal selidik kajian menggunakan Nordic Occupational Safety Climate Questionnaire (NOSACQ-50) iaitu satu alat diagnostik bagi menilai status iklim keselamatan sesebuah organisasi yang telah dibangunkan oleh kumpulan rangkaian pengkaji keselamatan pekerjaan Nordic. Soal selidik ini mempunyai asas teori yang jelas dan telah dibangunkan berdasarkan teori organisasi, teori iklim keselamatan dan hasil empirikal daripada berbagai kajian antarabangsa serta merupakan alat yang sah, boleh dipercayai dan boleh digunakan untuk negara, industri atau syarikat yang berlainan (Kines et al., 2011). Semua item di dalam soal selidik dijawab dengan cara yang sama iaitu empat peringkat Skala Likert. Ianya mudah dipindahkan ke dalam bentuk kuantitatif (Boone, 2012). Data kajian 
dianalisis menggunakan Statistical Package for the Social Sciences (SPSS) versi 17.0 dengan teknik deskriptif. Analisis desktiptrif digunakan untuk mengolah data dalam bentuk min dan peratusan.

\section{Hasil kajian dan perbincangan}

\section{Dimensi 1: Keutamaan, komitmen dan kecekapan keselamatan pihak pengurusan}

Tiga dimensi iklim keselamatan berkaitan persepsi terhadap pengendalian aspek keselamatan oleh pihak pengurusan ialah keutamaan, komitmen dan kecekapan keselamatan pihak pengurusan, pemerkasaan aspek keselamatan pihak pengurusan dan keadilan keselamatan pihak pengurusan. Pihak pengurusan yang dilihat memberi keutamaan, komited dan cekap mengendalikan isu-isu yang melibatkan keselamatan terutamanya di tempat kerja dapat mewujudkan iklim keselamatan yang baik di sesebuah organisasi (Zohar, 1980). Penilaian iklim keselamatan berkaitan Dimensi Keutamaan, Komitmen Dan Kecekapan Keselamatan Pihak Pengurusan memberikan nilai skor min keseluruhan sebanyak 2.89 yang menggambarkan tahap iklim keselamatan berkaitan dimensi ini yang agak rendah di MOA.

Majoriti responden bersetuju terhadap item positif berkaitan komitmen pihak pengurusan mempromosi keselamatan dan kecekapan pihak pengurusan mengendalikan aspek keselamatan, di mana peratusan bersetuju bahawa pihak pengurusan "menggalakkan peraturan diikuti", "memastikan maklumat berkaitan keselamatan diterima pekerja", "berupaya mengendalikan keselamatan di tempat kerja" dan "memastikan masalah keselamatan diperbetul segera" adalah masing-masing sebanyak 94.2\%, 85.3\%, 89.3\% dan 93.6\% (Rajah 1). Walaupun aspek komitmen dan kecekapan pihak pengurusan MOA mengendalikan hal-hal keselamatan di tempat kerja mencatatkan keputusan majoriti bersetuju tetapi keputusan sebaliknya dihasilkan berkaitan aspek keutamaan keselamatan oleh pihak pengurusan. Majoriti responden iaitu sebanyak 57.5\% tidak bersetuju bahawa "pihak pengurusan mengutamakan keselamatan berbanding produktiviti organisasi" (Rajah 1) di mana 45.9\% daripada jumlah berkenaan adalah respons daripada Kumpulan Sokongan dan $11.7 \%$ lagi adalah daripada Kumpulan P\&P.

Analisis bagi item negatif turut menggambarkan persepsi sama terhadap aspek komitmen dan kecekapan pihak pengurusan mengendalikan hal keselamatan serta keutamaan aspek keselamatan. Majoriti responden tidak bersetuju dengan item bahawa pihak pengurusan "tidak peduli sekiranya pekerja mengabaikan keselamatan", "mengabaikan risiko yang dikesan tanpa mengambil sebarang tindakan" dan "kurang keupayaan untuk mengendalikan aspek keselamatan secara betul di tempat kerja" iaitu masing-masing sebanyak 91.7\%, 90.8\% dan 93.6\%. Sumbangan responden Kumpulan P\&P kepada jumlah majoriti tidak bersetuju dengan setiap item berkenaan adalah masing-masing sebanyak $36.1 \%$, 36.1\% dan $38.0 \%$ manakala sumbangan responden Kumpulan Sokongan pula adalah masing-masing sebanyak 55.6\%, 54.7\% dan 55.6\%. Namun majoriti responden pula bersetuju bahawa pihak pengurusan "membenarkan pekerja mengambil risiko semasa jadual kerja yang ketat" iaitu sebanyak 55.2\% di mana 40.5\% adalah respons daripada Kumpulan Sokongan dan 14.7\% lagi adalah daripada Kumpulan P\&P. Dapatan ini membayangkan persepsi yang selaras dengan analisis item positif bahawa pihak pengurusan lebih mengutamakan produktiviti organisasi berbanding keselamatan. 


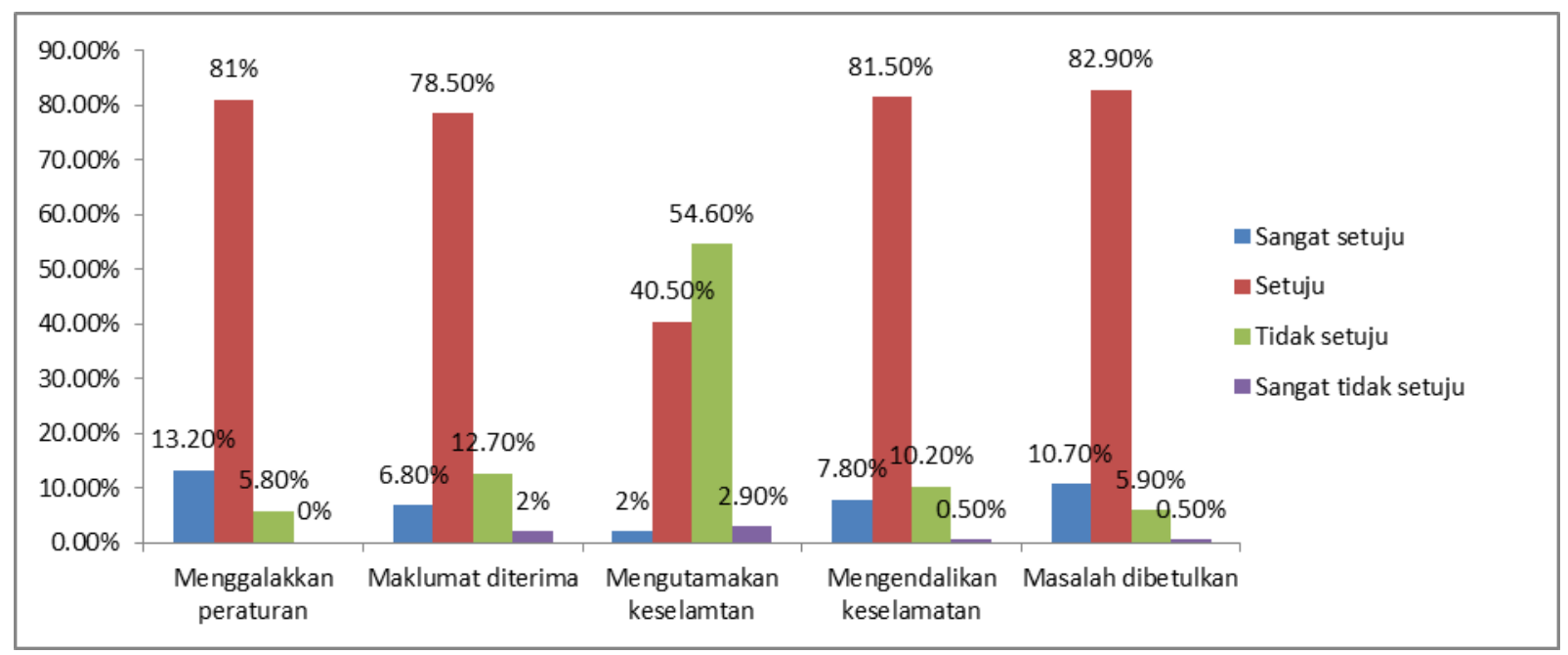

Rajah 1. Persepsi terhadap dimensi keutamaan, komitmen dan kecekapan keselamatan pihak pengurusan: Item positif

Pihak pengurusan yang mengutamakan keselamatan sepatutnya tidak teragak-agak untuk memberhentikan kerja tanpa mengira kos yang terpaksa ditanggung jika aspek keselamatan diabaikan (Health and Safety Executive UK, 2005). Selain itu perkara yang diutamakan atau dikehendaki oleh sesebuah organisasi juga ditunjukkan melalui penggubalan dasar kerana dasar menjadi panduan kepada pekerja bagaimana untuk bertindak mengikut kemahuan majikan (Von Solms, 2004). Walau bagaimanapun didapati tiada dasar berkaitan keselamatan dan kesihatan pekerjaan yang digubal di MOA. Ini adalah berlainan sekali jika dibandingkan dengan dasar berkaitan pembangunan industri pertanian yang menjadi core business MOA seperti Dasar Pertanian Negara dan Dasar Agromakanan Negara atau dasar bagi meningkatkan tahap penyampaian perkhidmatan organisasi seperti Pelan Strategik Kementerian yang digubal, dikemas kini, didokumen dan diwar-warkan kepada semua warga MOA, pihak industri dan orang awam.

\section{Dimensi 2: Pemerkasaan aspek keselamatan oleh pihak pengurusan}

Pemerkasaan aspek keselamatan oleh pihak pengurusan merupakan penurunan kuasa pihak pengurusan kepada pekerja yang memperlihatkan kepercayaan pihak pengurusan terhadap keupayaan dan kebolehan pekerja dalam membuat pertimbangan berkaitan aspek keselamatan. Kepercayaan pihak pengurusan terhadap pekerja akan mewujudkan rasa tanggung-jawab pekerja untuk membalas sebaik mungkin kepercayaan yang diberikan kepada mereka (Mayer et al., 1995), di mana dalam aspek kajian ini adalah dengan memperkukuhkan aspek keselamatan semasa di tempat kerja. Kajian mendapati tahap iklim keselamatan berkaitan Dimensi Pemerkasaan Aspek Keselamatan Oleh Pihak Pengurusan di MOA adalah rendah di mana nilai skor min secara keseluruhan yang diperoleh bagi dimensi ini sebanyak 2.56.

Majoriti responden bersetuju bahawa pihak pengurusan berusaha memperkasakan pekerja dengan "mereka bentuk rutin keselamatan yang bermakna dan berfungsi" iaitu sebanyak $81.5 \%$, "memastikan pekerja dapat mengendalikan aspek keselamatan di persekitaran kerja" iaitu 89.8\% dan "memastikan pekerja mempunyai kecekapan yang tinggi berkaitan keselamatan dan risiko pekerjaan" iaitu 72.2\% (Rajah 2). Namun nilai skor min keseluruhan dimensi ini dijejaskan oleh aspek bersabit penglibatan pekerja dalam membuat keputusan berkaitan keselamatan. Analisis 
item negatif berkaitan aspek penglibatan pekerja dalam membuat keputusan yang berkaitan keselamatan juga memberikan hasil dapatan yang selaras dengan analisis item positif. Majoriti responden bersetuju bahawa pihak pengurusan tidak mempertimbangkan cadangan pekerja mengenai keselamatan dan tidak pernah meminta pendapat pekerja sebelum membuat keputusan mengenai keselamatan iaitu masing-masing merekodkan peratusan sebanyak $67.8 \%$ dan $65.3 \%$. Sumbangan oleh responden Kumpulan P\&P kepada jumlah majoriti tidak bersetuju dengan kedua-dua item tersebut adalah sebanyak 32.2\% dan $29.3 \%$ manakala sumbangan responden Kumpulan Sokongan pula adalah sebanyak 35.6\% dan $36.0 \%$.

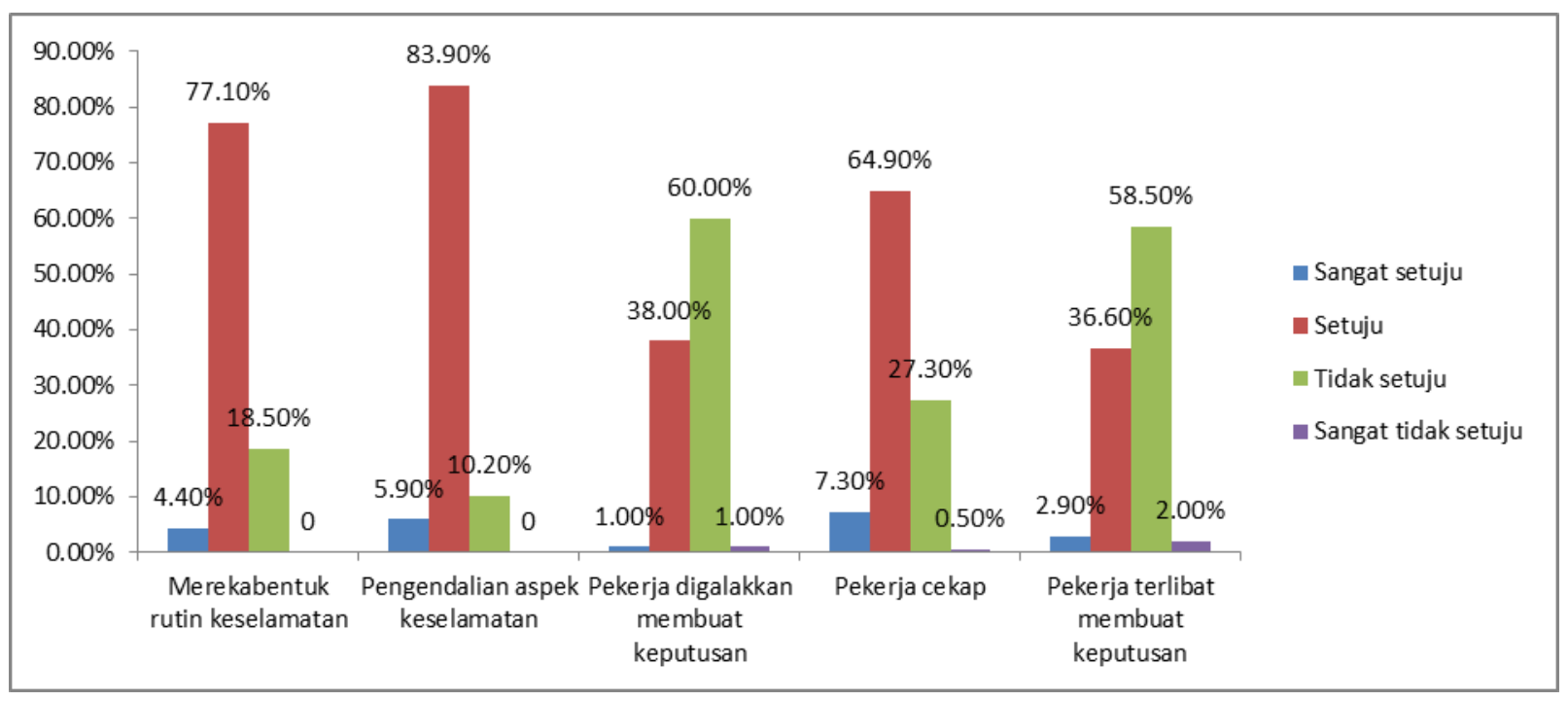

Rajah 2. Persepsi terhadap dimensi pemerkasaan aspek keselamatan oleh pihak pengurusan: Item positif

\section{Dimensi 3: Keadilan keselamatan pihak pengurusan}

Prestasi keselamatan yang baik di tempat kerja dipengaruhi oleh pengendalian insiden kemalangan dan kemalangan nyaris di tempat kerja secara adil oleh pihak pengurusan. Walaupun kegagalan untuk mendisiplinkan pekerja yang tidak mengendahkan keselamatan boleh menjejaskan prestasi keselamatan sesebuah organisasi tetapi dalam masa yang sama budaya terlalu menyalahkan pekerja yang terlibat dengan kemalangan atau kemalangan nyaris boleh menjadi penghalang kepada pengendalian keselamatan pekerjaan secara berkesan (Hasish \& ElBialy, 2013). Melalui analisis yang dijalankan, nilai skor min keseluruhan bagi Dimensi Keadilan Keselamatan Oleh Pihak Pengurusan di MOA adalah 3.00 iaitu menggambarkan tahap iklim keselamatan yang agak tinggi bagi dimensi ini.

Nilai skor min keseluruhan yang agak baik ini disumbangkan melalui majoriti responden yang menyatakan bersetuju dengan item positif dan tidak bersetuju dengan item negatif dalam soal selidik yang dijalankan. Peratusan majoriti bersetuju yang melebihi $90 \%$ dihasilkan bagi item pihak pengurusan "mengambil informasi yang tepat dalam penyiasatan kemalangan", "mendengar dengan teliti maklumat daripada pekerja yang terlibat dengan kemalangan" dan "melayan pekerja yang terlibat dengan kemalangan secara adil" iaitu masing-masing sebanyak 91.3\%, 91.7\% dan 95.1\% (Rajah 3). Sumbangan responden Kumpulan P\&P kepada peratusan majoriti bersetuju dengan setiap item berkenaan adalah masing-masing sebanyak 37.6\%, 36.1\% dan $37.6 \%$ manakala sumbangan responden Kumpulan Sokongan pula adalah masing-masing 
sebanyak 53.7\%, 55.6\% dan 57.5\%. Satu lagi item positif iaitu pihak pengurusan "melihat kepada punca kemalangan dan bukan orang yang bersalah apabila kemalangan berlaku", mencatatkan peratusan majoriti bersetuju sebanyak $86.8 \%$ (Rajah 3), di mana 33.6\% daripadanya adalah responden Kumpulan P\&P dan 53.2\% lagi Kumpulan Sokongan.

Bagi item negatif pula, analisis menunjukkan $84.4 \%$ responden tidak bersetuju bahawa pekerja "tidak melaporkan kemalangan nyaris kerana takut dikenakan tindakan" di mana $32.7 \%$ adalah responden Kumpulan P\&P dan 51.7\% Kumpulan Sokongan. Selanjutnya 91.2\% responden tidak bersetuju bahawa pihak pengurusan "menyalahkan pekerja apabila kemalangan berlaku" di mana 35.6\% adalah responden Kumpulan P\&P dan 55.6\% lagi Kumpulan Sokongan.

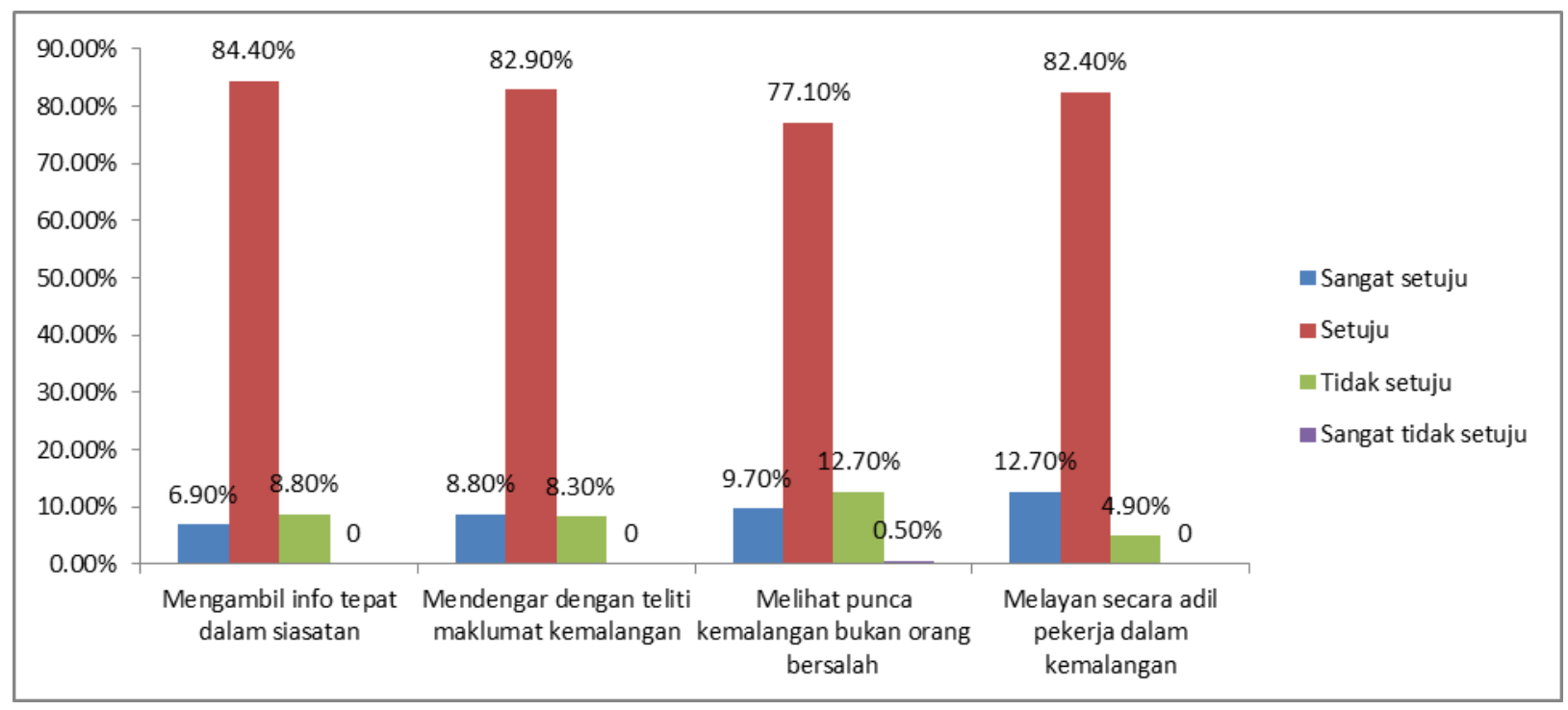

Rajah 3. Persepsi terhadap dimensi keadilan keselamatan pihak pengurusan: Item positif

Menurut Weiner et al. (2008), keadilan keselamatan boleh diperhatikan daripada empat aspek iaitu keadilan dalam pengagihan (distributive), prosedur (prosedural), hubungan perorangan (interpersonal) dan maklumat (informational). Keadilan daripada aspek pengagihan dan prosedur adalah lebih bersifat struktural manakala keadilan daripada aspek hubungan perorangan dan maklumat lebih bersifat sosial. Dalam hubungan ini, adalah agak sukar untuk mengaitkan hasil penilaian dimensi iklim keselamatan pihak pengurusan daripada aspek keadilan pengagihan dan prosedur kerana tiada peraturan atau tatacara penyiasatan kemalangan atau aduan dibangunkan di MOA yang boleh membuktikan sama ada pengagihan sumber dan kaedah penyiasatan dilaksanakan secara teratur dan konsisten (Kadir et al., 2017a).

Sungguh pun demikian saluran untuk mengemukakan laporan atau aduan kemalangan dan kerosakan telah dimaklumkan oleh Cawangan Pentadbiran kepada semua bahagian di MOA. Aduan boleh disampaikan secara terus kepada wakil keselamatan setiap bahagian, syarikat penyelenggara perkhidmatan atau Call Centre Jabatan Kerja Raya. Pengadu akan menerima maklum balas yang segera iaitu dalam hari yang sama daripada pihak yang berkenaan manakala penyiasatan dan tindakan pembetulan juga dilaksanakan segera. Selain itu tindakan yang diambil terhadap aduan kemalangan atau kerosakan di MOA memfokuskan kepada punca kemalangan dan bukan mengenakan hukuman kepada pekerja yang terlibat dengan insiden kemalangan atau kerosakan. Sebagai contoh, siasatan kes yang melibatkan kemalangan dan kemalangan nyaris kereta pejabat yang dipandu oleh pemandu kementerian mendapati kemalangan berlaku berpunca 
daripada keletihan pemandu yang terpaksa bertugas dalam jangka masa yang panjang. Justeru tindakan telah diambil untuk memastikan penggiliran waktu bertugas bagi mengelakkan tekanan kepada pemandu. Maklumat ini menunjukkan adanya keadilan keselamatan oleh pihak pengurusan MOA daripada aspek keadilan maklumat iaitu dengan melihat punca kemalangan dan segera mengambil tindakan; serta daripada aspek keadilan hubungan perorangan iaitu dengan bersifat prihatin kepada pekerja yang terlibat dengan kemalangan, seperti mana dinyatakan oleh Weiner et al. (2008).

\section{Dimensi 4: Komitmen keselamatan pekerja}

Kajian iklim keselamatan oleh Clarke (2010) mendapati individu lebih komited kepada kumpulan kerja berbanding organisasi. Sehubungan dengan itu, persepsi berkaitan komitmen pekerja yang ditunjukkan menerusi norma atau amalan di tempat kerja amat penting dalam kajian iklim keselamatan. Analisis kajian menunjukkan tahap iklim keselamatan bagi Dimensi Komitmen Keselamatan Pekerja di MOA adalah agak tinggi di mana nilai skor min keseluruhan yang diperolehi adalah sebanyak 3.04.

Ketiga-tiga item positif berkaitan dimensi ini memberikan peratusan majoriti bersetuju melebihi $94 \%$. Majoriti $94.2 \%$ bersetuju dengan item pekerja bersama-sama "berusaha untuk mencapai tahap keselamatan yang tinggi" dan item "memastikan tempat kerja adalah teratur dan bersih" manakala majoriti $97.6 \%$ bersetuju pekerja bersama-sama "menolong satu sama lain untuk bekerja secara selamat" (Rajah 4). Analisis juga menunjukkan sumbangan Kumpulan P\&P kepada jumlah majoriti bersetuju dengan ketiga-tiga item berkenaan adalah masing-masing sebanyak 37.1\%, 38.1\%, dan 38.6\% manakala sumbangan Kumpulan Sokongan pula adalah masing-masing sebanyak 57.1\%, 56.1\%, dan 59\%. Dapatan ini disokong maklumat bahawa MOA telah dianugerahkan Persijilan Persekitaran Berkualiti daripada Perbadanan Produktiviti Malaysia (MPC) sejak 29 November 2012 sehingga kini, kerana kejayaan setiap Bahagian di MOA memastikan persekitaran kerja yang selamat, sihat dan selesa melalui amalan sisih, susun, sapu, seragam dan sentiasa amal (5S).

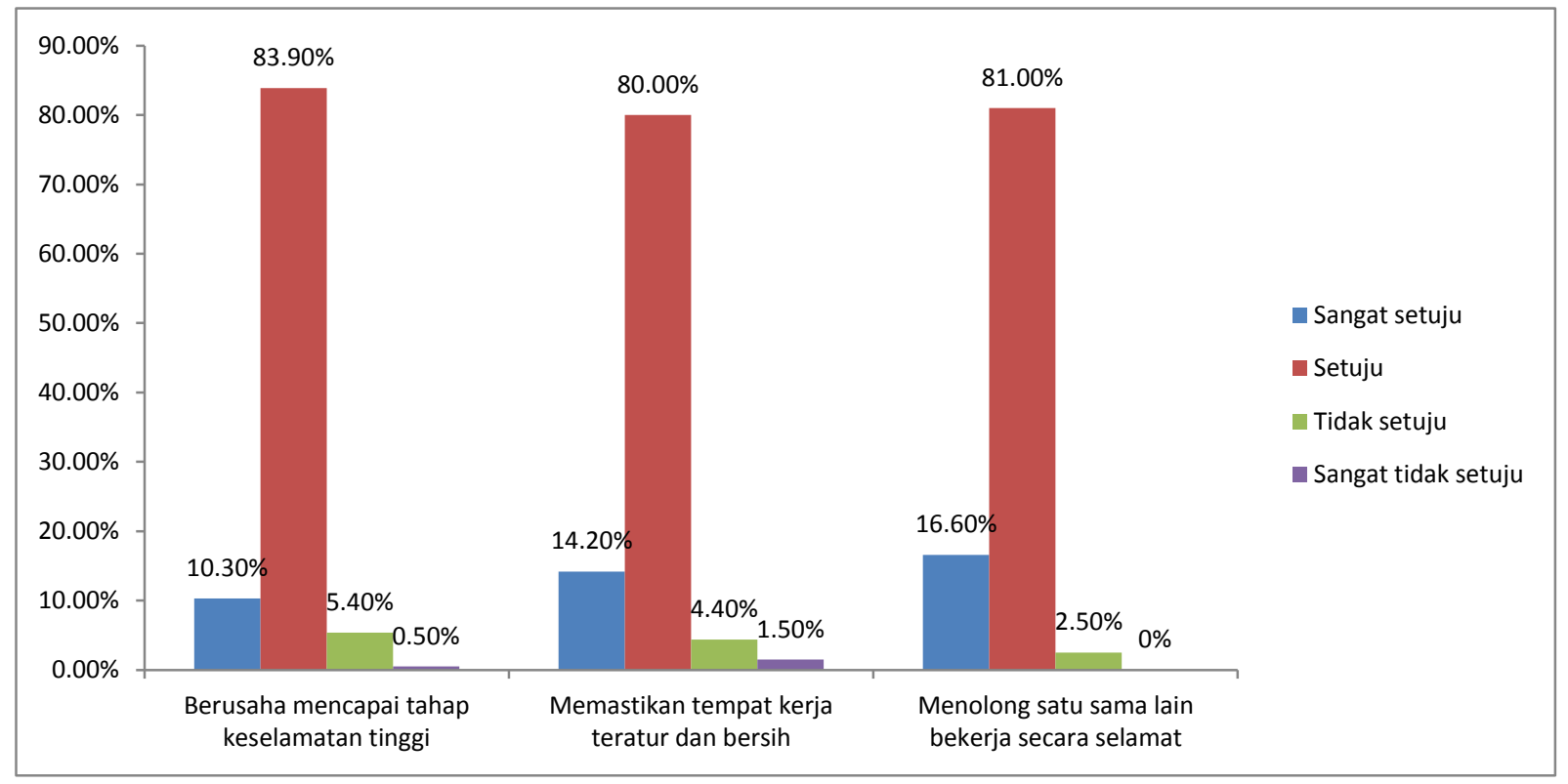

Rajah 4. Persepsi terhadap dimensi komitmen keselamatan pekerja: Item positif 
Bagi item negatif pula, majoriti responden tidak bersetuju bahawa pekerja "tidak mengambil berat keselamatan antara satu sama lain" dan "tidak bertanggung-jawab atas keselamatan satu sama lain" di mana kedua-dua item ini mencatat peratusan tidak bersetuju sebanyak $93.7 \%$ iaitu masing-masing $36.6 \%$ dan $37.1 \%$ daripada responden Kumpulan P\&P serta $57.1 \%$ dan 56.6\% responden Kumpulan Sokongan. Walau bagaimanapun peratusan majoriti yang tidak bersetuju bahawa pekerja "mengelak menangani risiko yang ditemui" pula adalah lebih rendah iaitu sebanyak $82.0 \%$ di mana $32.7 \%$ adalah responden Kumpulan P\&P dan $49.3 \%$ Kumpulan Sokongan. Kajian oleh Wang dan Chow (2003) juga mendapati terdapat kecenderungan syarikat untuk menyerahkan pengendalian risiko kepada pihak lain khususnya kontraktor penyelenggaraan apabila syarikat menganggarkan risiko mampu dikawal oleh kontraktor.

\section{Dimensi 5: Keutamaan keselamatan dan risiko tidak diterima pekerja}

Faktor tekanan yang berkaitan dengan bebanan dan tempoh masa untuk menyiapkan kerja sering menjadi dilema kepada pekerja untuk memberi keutamaan kepada aspek keselamatan di tempat kerja (Flin et al., 2000). Selain itu, keutamaan terhadap aspek keselamatan juga turut terjejas sekiranya penerimaan atau pengambilan risiko menjadi norma pekerja (Mearns et al., 1998). Penilaian iklim keselamatan berkaitan Dimensi Keutamaan Keselamatan Dan Risiko Tidak Diterima Pekerja memberikan nilai skor min keseluruhan sebanyak 2.88 yang menggambarkan tahap iklim keselamatan berkaitan dimensi ini yang agak rendah di MOA.

Skor min keseluruhan bagi dimensi ini terjejas kerana majoriti agak rendah bersetuju dengan item positif dan tidak bersetuju dengan beberapa item negatif. Terdapat satu item positif berkaitan Dimensi Keutamaan Keselamatan Dan Risiko Tidak Diterima Pekerja terkandung dalam soal selidik kajian. Analisis yang dijalankan menunjukkan hanya $69.8 \%$ responden bersetuju bahawa pekerja "tidak mengambil risiko walaupun pada waktu jadual kerja yang ketat" (Rajah 5). Peratusan bersetuju ini terdiri daripada 25.9\% Kumpulan P\&P dan 43.9\% Kumpulan Sokongan.

Seterusnya analisis item negatif menunjukkan majoriti responden tidak bersetuju bahawa "kemalangan kecil adalah normal dalam kerja mereka" iaitu sebanyak 81.9\%, tidak bersetuju "tingkah laku merbahaya boleh diterima" iaitu 91.3\% dan tidak bersetuju "kerja mereka tidak sesuai untuk orang yang pengecut" iaitu 89.3\%. Sumbangan oleh responden Kumpulan P\&P kepada peratusan majoriti tidak bersetuju dengan setiap item berkenaan adalah masing-masing sebanyak $33.2 \%, 37.1 \%$, dan $35.1 \%$ manakala sumbangan responden Kumpulan Sokongan pula adalah masing-masing sebanyak 48.7\%, 54.2\%, dan 54.2\%. Walau bagaimanapun peratusan majoriti tidak bersetuju ini menurun bagi item negatif berkaitan persepsi bahawa "risiko tidak dapat dielakkan" iaitu sebanyak 71.7\%, "melanggar peraturan untuk menyiapkan kerja tepat pada masanya" iaitu $74.1 \%$ dan "tidak kesah mengambil risiko di tempat kerja" iaitu 76.2\%.

Dapatan ini disokong dengan senario yang berlaku bahawa arahan daripada pihak pengurusan atasan yang diklasifikasikan sebagai "segera" atau "serta merta" perlu dilaksanakan dalam tempoh masa yang pendek menyebabkan aspek keselamatan diabaikan. Slovic (1987) menyatakan individu tidak kisah mengambil risiko apabila merasakan lebih banyak faedah akan diperoleh dalam urusan yang dilaksanakan seperti menjadikan kerja lebih mudah dan cepat. Antara risiko diambil pekerja di MOA adalah terhalang akses kecemasan kerana kenderaan diletak di tempat yang tidak sewajarnya bagi mengejar perakam waktu, tersepit kerana mengejar dan menahan lif, tertimpa objek yang berat kerana cuai dan tergesa-gesa untuk mengambil fail di tempat yang tinggi serta sakit tulang belakang, kepala dan mata kerana duduk dan menggunakan 
komputer untuk tempoh masa yang panjang bagi menyiapkan kertas kerja atau semasa bermesyuarat.

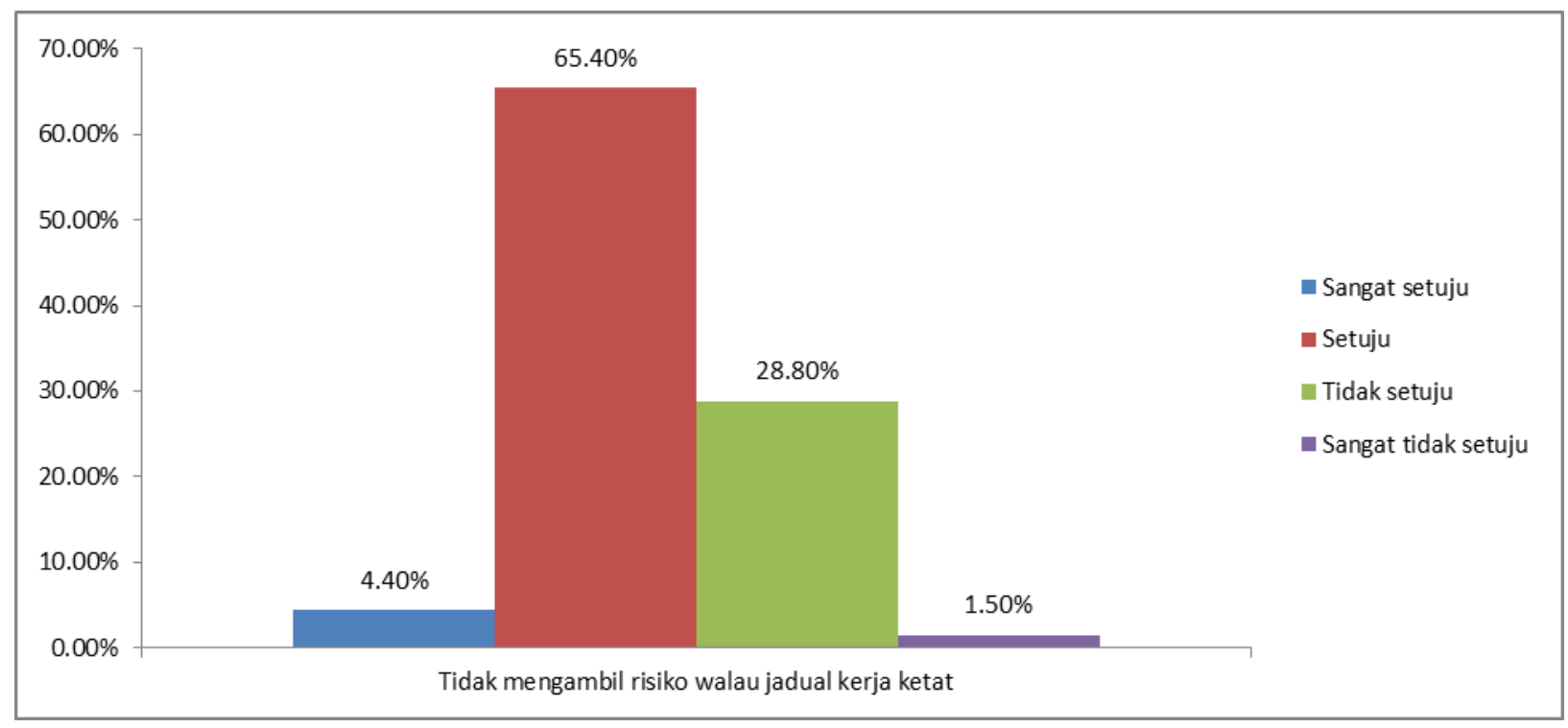

Rajah 5. Persepsi terhadap dimensi keutamaan keselamatan dan risiko tidak diterima oleh pekerja: Item positif

\section{Dimensi 6: Komunikasi, pembelajaran dan kepercayaan terhadap kompetensi rakan sekerja}

Komunikasi merangsang proses pembelajaran bagi memperbaiki prestasi keselamatan. Selain komunikasi dan pembelajaran, kepercayaan terhadap kompetensi sesama rakan sekerja akan meningkatkan motivasi pekerja untuk bertindak dengan lebih selamat (Kines et al., 2011). Analisis penilaian iklim keselamatan berkaitan Dimensi Komunikasi, Pembelajaran Dan Kepercayaan Terhadap Kompetensi Rakan Sekerja menghasilkan nilai skor min keseluruhan sebanyak 3.01 yang menggambarkan tahap iklim keselamatan berkaitan dimensi ini yang agak tinggi.

Analisis item positif menunjukkan majoriti bersetuju melebihi 90\% dicatatkan bagi aspek komunikasi di mana 95.5\%, responden bersetuju pekerja "mencari penyelesaian sekiranya seseorang mengemukakan masalah keselamatan", 94.2\% bersetuju pekerja "mengambil berat pendapat dan cadangan rakan", 91.2\% bersetuju pekerja "berbincang isu keselamatan apabila isu berlaku" dan $96.1 \%$ bersetuju pekerja boleh berbincang mengenai keselamatan secara bebas dan terbuka (Rajah 6). Sumbangan Kumpulan P\&P kepada peratusan bersetuju dengan item-item berkenaan adalah masing-masing sebanyak 38.0\%, 37.6\%, 36.6\% dan 38.1\% manakala daripada kumpulan Sokongan adalah sebanyak 57.5\%, 56.6\%, 54.6\% dan 58.0\%.

Peratusan majoriti bersetuju melebihi $90 \%$ juga dicatatkan bagi aspek pembelajaran dan aspek kepercayaan terhadap kompetensi rakan sekerja. Sebanyak 92.2\% responden bersetuju bahawa pekerja "belajar daripada pengalaman untuk mengelakkan kemalangan semasa bekerja", 98.0\% bersetuju bahawa pekerja "berasa selamat apabila bekerja bersama" dan $97.2 \%$ bersetuju bahawa pekerja "mempercayai keupayaan masing-masing dalam memastikan keselamatan di persekitaran kerja mereka".

Sungguh pun majoriti responden menyatakan bersetuju aspek keselamatan boleh dibincangkan secara bebas dan terbuka di MOA namun analisis item negatif menunjukkan lebih 
daripada separuh responden bersetuju bahawa pekerja jarang membincangkan hal keselamatan pekerjaan iaitu 53.2\% di mana 12.2\% adalah Kumpulan P\&P manakala 41\% lagi Kumpulan Sokongan. Keadaan persekitaran kerja di MOA adalah selamat dan tidak berisiko dan sekiranya berlaku masalah sekali pun ia hanyalah kerosakan kecil, justeru perbincangan mengenai hal keselamatan jarang berlaku. Kajian Siti Fatimah (2011) menunjukkan kefahaman dan pengetahuan risiko di tempat kerja mempunyai hubungan positif yang kuat dengan latihan keselamatan.

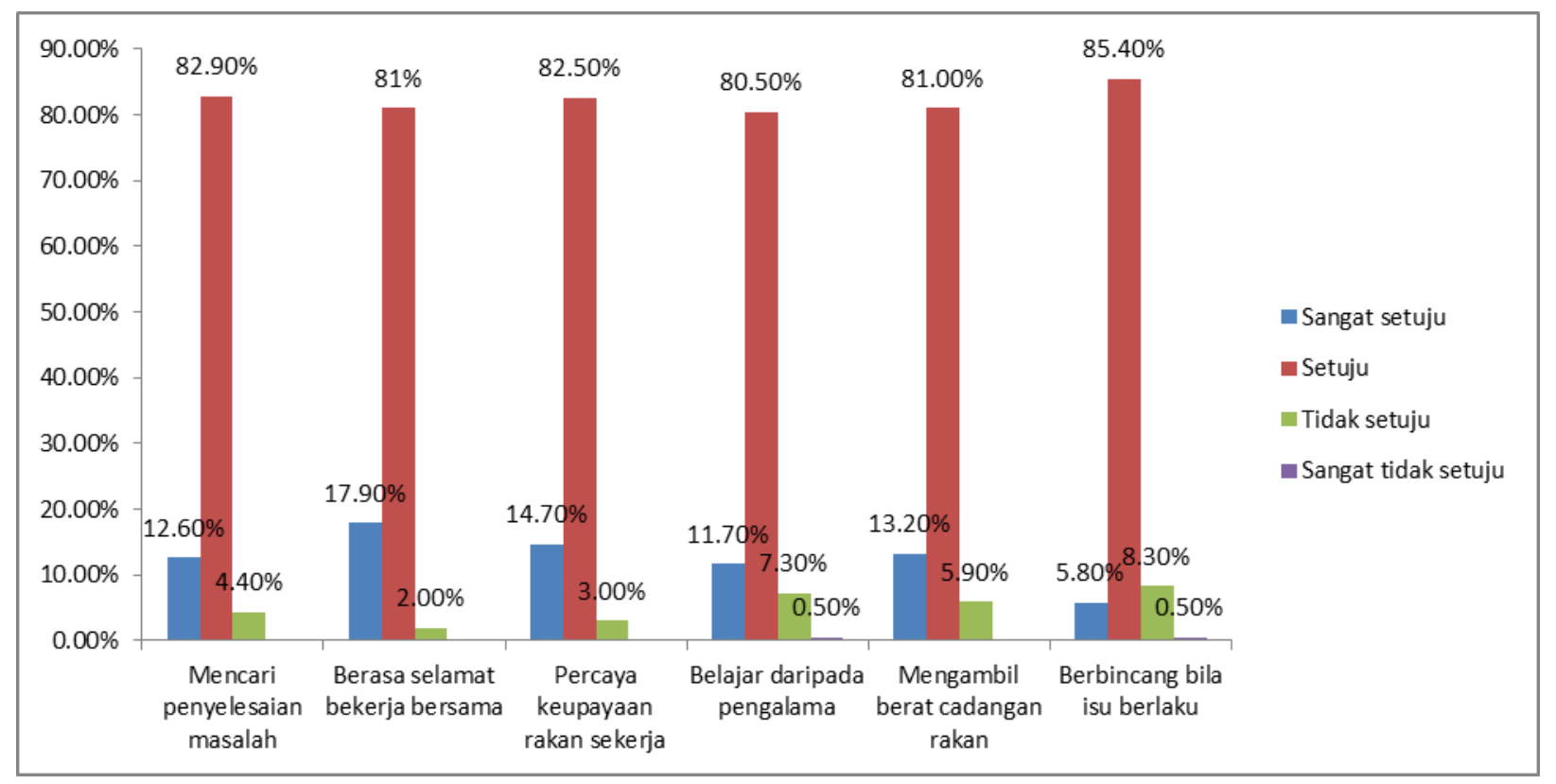

Rajah 6. Persepsi terhadap dimensi komunikasi, pembelajaran dan kepercayaan terhadap kompetensi rakan sekerja: Item positif

Dapatan kajian mendapati warga MOA didedahkan dengan latihan kebakaran sahaja. Oleh itu, persepsi responden bahawa persekitaran kerja dalam pejabat di MOA adalah selamat dan tidak berisiko dipengaruhi oleh kurangnya pendedahan dan latihan keselamatan pekerjaan. Tiada insiden kemalangan yang dilaporkan dalam tempoh masa yang panjang menyebabkan isu keselamatan jarang dibincangkan dan meningkatkan persepsi pekerja bahawa persekitaran kerjanya adalah selamat dan tidak berisiko (Rundmo, 1995).

\section{Dimensi 7: Kepercayaan pekerja terhadap keberkesanan sistem keselamatan}

Penilaian persepsi terhadap sistem keselamatan yang merangkumi objektif keselamatan, pegawai keselamatan, pemeriksaan keselamatan, latihan keselamatan bukan merupakan audit bagaimana sesuatu sistem itu dilaksanakan di tempat kerja yang menjadi lokasi kajian. Sebaliknya penilaian yang dibuat adalah bertujuan untuk mendapatkan persepsi pekerja tentang keberkesanan sistem keselamatan sebagai cara untuk mencapai standard keselamatan yang baik (Hale, 2000; Kadir et al., 2017b). Melalui analisis yang dijalankan, nilai skor min keseluruhan bagi Dimensi Kepercayaan Pekerja Terhadap Keberkesanan Sistem Keselamatan adalah 3.34 iaitu menggambarkan tahap iklim keselamatan yang tinggi bagi dimensi ini. 
Secara keseluruhan analisis dimensi ini mendapati hampir kesemua responden mempunyai persepsi bahawa sistem pengurusan keselamatan yang merangkumi wakil keselamatan yang baik, latihan keselamatan, pemeriksaan keselamatan, perancangan awal dan matlamat keselamatan yang jelas adalah berkesan bagi mencapai prestasi keselamatan yang baik. Analisis item positif menunjukkan $100 \%$ responden bersetuju bahawa wakil keselamatan yang baik dan matlamat keselamatan yang jelas di tempat kerja adalah penting untuk mencegah kemalangan iaitu 39\% adalah responden Kumpulan P\&P dan 61.0\% Kumpulan Sokongan. Hampir 100\% responden juga bersetuju latihan dan pemeriksaan keselamatan baik untuk mencegah kemalangan dan mengenal pasti hazard iaitu sebanyak $99.5 \%$.

Analisis item negatif pula menunjukkan $99.5 \%$ responden tidak bersetuju dengan kenyataan bahawa latihan dan pemeriksaan keselamatan tidak bermakna atau berkesan kepada keselamatan di tempat kerja manakala $99.0 \%$ tidak bersetuju perancangan awal tidak bermakna bagi memastikan keselamatan di tempat kerja.

Kajian Kadir et al. (2016) juga menghasilkan dapatan yang sama di mana skor tahap iklim keselamatan yang tinggi dicatatkan bagi dimensi kepercayaan terhadap keberkesanan sistem keselamatan berbanding dimensi-dimensi yang lain. Menurut Mayer et al. (1995), kepercayaan boleh mewujudkan kerjasama dan membantu usaha menggembleng tenaga pekerja bagi menjayakan perancangan sesebuah organisasi. Ini menunjukkan terdapat peluang yang cerah untuk melibatkan pekerja dalam aktiviti pengurusan keselamatan di MOA.

\section{Kesimpulan}

Secara keseluruhan skor min iklim keselamatan di MOA adalah sebanyak 2.96 iaitu menunjukkan tahap iklim keselamatan yang agak rendah dan memerlukan penambahbaikan. Iklim keselamatan berkaitan pengendalian aspek keselamatan oleh pihak pengurusan adalah agak tinggi berkaitan dimensi keadilan keselamatan tetapi agak rendah berkaitan dimensi keutamaan, komitmen dan kecekapan keselamatan serta rendah berkaitan dimensi pemerkasaan keselamatan. Manakala iklim keselamatan berkaitan pengendalian aspek keselamatan oleh pihak pekerja pula adalah tinggi berkaitan dimensi kepercayaan terhadap keberkesanan sistem keselamatan, agak tinggi bagi kedua-dua dimensi komitmen serta dimensi komunikasi, pembelajaran dan kepercayaan terhadap kompetensi rakan sekerja tetapi agak rendah berkaitan dimensi keutamaan keselamatan dan risiko yang tidak diterima. Organisasi sentiasa mencari langkah untuk menguruskan aspek keselamatan di tempat kerja dengan lebih baik. Persepsi pekerja tentang pengendalian aspek keselamatan pihak pengurusan dan pekerja serta kepentingan sistem pengurusan keselamatan akan menentukan cara mereka berkelakuan sama ada secara berbahaya, berisiko atau selamat. Sehubungan dengan itu, iklim keselamatan menjadi faktor yang penting bagi menilai prestasi pengurusan keselamatan sesebuah organisasi.

\section{Rujukan}

Alli B.O. (2008). Fundamental principles of occupational health and safety. International Labour Office - Geneva. Dicapai pada 10 Februari 2014. http://www.ilo.org/wcmsp5/ groups/public/@dgreports/@dcomm/@publ/documents/publication/wcms_093550.pdf

Barling J., Loughlin C., \& Kelloway E.K. (2002). Development and test of a model linking 
safety-specific transformational leadership and occupational safety. Journal of Applied Psychology, 87, 488-96.

Boone H.N. (2012). Analyzing Likert Scale. Journal of Extension, 50(2).

Bosak J., Coetsee W.J., \& Cullinane S.J. (2013). Safety climate dimensions as predictors for risk behavior. Accident Analysis and Prevention, 55, 256-264.

Bryce G.K., \& Manga P. (1985). The effectiveness of Health and Safety Committees. Industrial Relations, 40(2), 257-283.

Carder B., \& Ragan P.W. (2003). A survey-based system for safety measurement and improvement. Journal of Safely Research, 34, 157-165.

Clarke S. (2010). An integrative model of safety climate: linking psychological climate and work attitudes to individual safety outcomes using meta-analysis. Journal of Occupational and Organizational Psychology, 83, 553-578.

Chew, N.A., Spickett, J.T., Rumchev, K.B., \& Dhaliwal, S. (2009). Assessing employee's perception on health and safety management in public hospitals. International Review of Business Research Papers, 5(4), 54-72.

Cooper, M.D. (2000). Towards a model of safety culture. Safety Science, 36, 111-136.

Cooper, M.D., \& Phillips, R.A. (2004). Exploratory analysis of the safety climate and safety behavior relationship. Journal of Safety Research, 35, 497-512.

Coyle, I.R., Sleeman, S.D., \& Adams, N. (1995). Safety climate. Journal of Safety Research, 26(4).

Diaz, R.I., \& Cabrera, D.D. (1997). Safety climate and attitude evaluation measures of organizational safety. Accident Analysis and Prevention, 29(5), 643-650.

Flin, R., Mearns, K., O'Connor, P., \& Bryden, R. 2000. Measuring safety climate: identifying the common features. Safety Science, 34, 177-192.

Hale, A.R. (2000). Culture's confusion. Safety Science, 34, 1-14.

Hashish, E.A.A., \& El-Bialy, G.G. (2013). Nurses' perceptions of safety climate and barriers to report medication errors. Life Science Journal, 10(1).

Health and Safety Executive. (2005). A review of safety culture and safety climate literature for the development of the safety culture inspection toolkit. Health and Safety Executive Research Report 367.

Huang Y.H., Ho M., Smith G.S., \& Chen P.Y. (2006). Safety climate and self-reported injury: assessing the mediating role of employee safety control. Accident Analysis and Prevention, 38, 425-433.

Ima Ilyani Ibrahim, Sarina Muhamad Noor, Noraini Nasirun \& Zulaiha Ahmad. (2012). Safety in the office: does it matter to the staff? Social and Behavioral Sciences, 50, 730-740.

Kadir Ariffin, Shaharuddin Ahmad, Jamaluddin Md Jahi, Muhamamd Rizal Razman, Kadaruddin Aiyub, Azahan Awang, \& Azhar Jaludin. (2012). Perception towards occupational safety and health aspects at institute of public higher learning: A case at Faculty of Science and Humanities Universiti Kebangsaan Malaysia. The Social Sciences, 7(3), 361-368.

Kadir Arifin, Roziah Abudin, Muhammad Rizal Razman, Zitty Sarah Ismail \& Maisarah Ahmad. (2016). Safety climate assessment on priority, commitment and the efficiency of safety management. Journal of Food, Agriculture \& Environment, 14(2),142-146. 
Kadir Arifin, Roziah Abudin, Muhammad Rizal Razman \& Zitty Sarah Ismail. (2017a). Safety of climate levels related to the safety management on empowerment dimension aspects. Information, 20, 7 (A), 4935-4940

Kadir Arifin, Kadaruddin Aiyub, Muhammad Rizal Razman, Zitty Sarah Ismail, Masdila Johari, Amirul Shazli Sahimi, Nik Raihan Nik Mansor \& Mohd Hafiidz Jaafar. (2017b) Perception of safety culture among workers in research universities in Malaysia. Journal of Food, Agriculture \& Environment, 15(3\&4),110-114.

Kines, P., Lappalainen, J., Mikkelsen, K.L., Olsen, E., Pousette, A., Tharaldsen, J., Tómasson, K., \& Törner, M. (2011). Nordic Safety Climate Questionnaire (NOSACQ-50): A new tool for diagnosing occupational safety climate. International Journal of Industrial Ergonomics, 41, 634-646.

Lu, C.S., \& Shang, K.C. (2005). An empirical investigation of safety climate in container terminal operators. Journal of Safety Research, 36, 297-308.

Mayer, R.C., Davis, J.H., \& Schoorman, F.D. (1995). An integrative model of organizational trust. Academy of Management Review, 20(3), 709-734.

Mearns, K., Flin, R., Gordon, R., \& Fleming, M. (1998). Measuring safety climate on offshore installations. Work \& Stress 12(3): 328-254.

Mearns, K., Hope, L., Ford, M.T., \& Tetrick, L.E. (2010). Investment in workforce health: exploring the implications for workforce safety climate and commitment. Accident Analysis \& Prevention, 42(5), 1445-1454.

Parimalam, P., Kamalamma, N., \& Ganguly, A.K. (2007). Knowledge, attitude and practice related to occupational health problems among garment workers in Tamil Nadu, India. Journal Occupational Health, 49, 528-34.

Petersen, P. (2005). Safety improvement. Perception survey can reveal strengths and weaknesses. Professional Safety: 45-48. Dicapai pada 15 Februari 2014 http://members.asse.org/pspdfs/45-48Jan2005.pd

Pidgeon, N.K. (1998). Safety culture: Key theoretical issues. Work and Stress, 2(3), 202-216.

Rundmo, T. (1995). Perceived risk, safety status and job stress among injured and non-injured employees on offshore petroleum installations. Journal of Safety Research, 26(2), 87-97.

Siti Fatimah Bahari. (2011). An investigation of safety training, safety climate and safety outcomes: a longitudinal study in a Malaysian manufacturing plant. Thesis Ph.D. Faculty of Humanities, University of Manchester

Smith, M., Cohen, H., Cohen, A., \& Cleveland, R. (1978). Characteristics of successful safety programs. Journal of Safety Research, 10(1), 5-15.

Slovic, P. (1987). Perception of risk. Science New Series, 236(4799), 280-285.

Von Solms, R, \& Von Solms, B. (2004). From policies to culture. Computers and Security, 23(4), 275-279.

Wang, M.T., \& Chow, H.U. (2003). Risk allocation and risk handling of highway projects in Taiwan. Journal of Management in Engineering, 19(2), 60-68

Ward, J., Haslam, C., \& Haslam, R. (2008). The impact of helath and safety management on organisation and their staff. Institution of Occupational Safety and Health, Loughborough University

Weiner, B.J., Hoobgood, C., \& Lewis, M.A. (2008). The meaning of justice in safety incident reporting. Social Science \& Medicine, 66, 403-413.

Wu, T.C., Liu, C.W., \& Lu, M.C. (2007). Safety climate in university and college laboratories: Impact of organizational and individual factors. Journal of Safety Research, 38, 91-102. 
Yeung, K.C., \& Chan, C.C. (2006). Measuring safety climate in elderly homes. Journal of Safety Research, 43, 9-20.

Zitty Sarah Ismail, Kadir Arifin, Kadaruddin Aiyub, Muhammad Rizal Razman, Norfadillah Derahim, \& Nurul Nabihah Abbas. (2017). Assessing of safety culture in the research university in Malaysia. Journal of Food, Agriculture and Environment, 15(2), 102-106.

Zohar, D. (1980). Safety climate in industrial organizations: Theoretical and applied implications. Journal of Applied Psychology, 65(1), 96-102. 